\title{
Implications of Oxytocin in Human Linguistic Cognition: From Genome to Phenome
}

\author{
Constantina Theofanopoulou * \\ Department of General Linguistics, University of Barcelona, Barcelona, Spain
}

The neurohormone oxytocin (OXT) has been found to mediate the regulation of complex socioemotional cognition in multiple ways both in humans and other animals. Recent studies have investigated the effects of OXT in different levels of analysis (from genetic to behavioral) chiefly targeting its impact on the social component and only indirectly indicating its implications in other components of our socio-interactive abilities. This article aims at shedding light onto how OXT might be modulating the multimodality that characterizes our higher-order linguistic abilities (vocal-auditory-attentional-memory-social systems). Based on evidence coming from genetic, EEG, fMRI, and behavioral studies, I attempt to establish the promises of this perspective with the goal of stressing the need for neuropeptide treatments to enter clinical practice.

OPEN ACCESS

Edited by:

Mitsuhiro Kawata,

Kyoto Prefectural University of

Medicine, Japan

Reviewed by:

Yoichi Ueta

University of Occupational and

Environmental Health, Japan

Haruhiro Higashida,

Kanazawa University Research Center for Child Mental Development, Japan

${ }^{*}$ Correspondence: Constantina Theofanopoulou constantinaki@hotmail.com

Specialty section:

This article was submitted to Neuroendocrine Science,

a section of the journal

Frontiers in Neuroscience

Received: 06 March 2016

Accepted: 31 May 2016

Published: 14 June 2016

Citation:

Theofanopoulou C (2016) Implications of Oxytocin in Human Linguistic

Cognition: From Genome to Phenome. Front. Neurosci. 10:271. doi: 10.3389/fnins.2016.00271
Keywords: oxytocin, language, alpha rhythm, OXTR, POU3F2, LNPEP, FOXP2, CNTNAP2

\section{INTRODUCTION}

The nine amino acid peptide oxytocin (OXT) is involved in an array of physiological and pathophysiological processes, with some of those most commonly reported in the literature being pregnancy and uterine contractions, milk ejection, sexual activity, pain modulation, social interaction and bonding, parental care, and attention to socially-relevant stimuli (for a good review see Meyer-Lindenberg et al., 2011). From another perspective, malfunctions of the oxytocinergic system have been reported in cases of Autism Spectrum Disorder, Schizophrenia, Obsessive Compulsive Disorder, Phobia, Prader-Willi Syndrome and Williams Syndrome, providing strong functional links to the social and emotional modules that all these cases share (Leckman et al., 1994; Lopatina et al., 2012; De Berardis et al., 2013; Grinevich et al., 2015; Haas and Smith, 2015). This broad perspective of the literature indicates that OXT impacts a wide spectrum of neurobehavioral systems.

Here I put forth the hypothesis that OXT also has a significant role in our linguistic abilities, ranging from modulating genes involved in spoken-language acquisition to modulating our motivation to communicate. In building this hypothesis, I follow an approach I have argued in Theofanopoulou and Boeckx (2015) in the context of cognitive phylogenies, where for a hypothesis to be valid in the Language Sciences, there needs to be evidence at multiple levels of biological organization, from genetics to ultimately the behavioral level (Fisher, 2015). Thus, I appeal to relevant findings from a multitude of studies, touching upon all the following levels of analysis: genome, connectome, dynome (brain oscillations), cognome, and phenome (See Figure 1). I also develop my hypothesis from a translational viewpoint among non-human animal studies and humans, including the molecular studies of OXT to its social functions in communication. I conclude that OXT most 


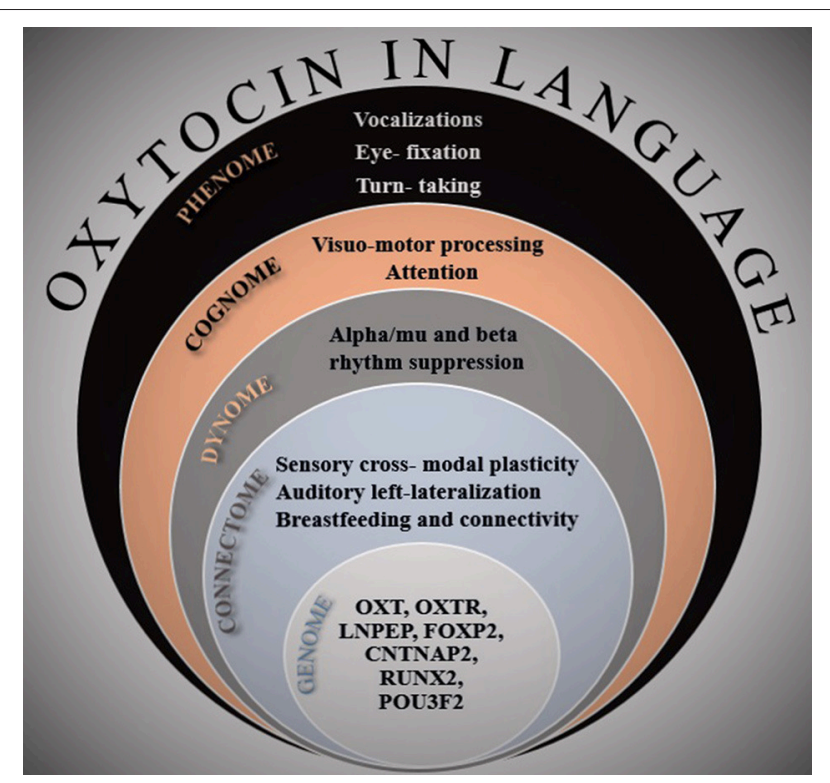

FIGURE 1 | A multi-dimensional illustration of the evidence presented in the paper. At every level of analysis, the most important findings that are related to the role of oxytocin in linguistic cognition are listed.

probably globally affects brain components that are tightly interwoven with the pinnacle of our social expressions, namely the sensory, motor, and more cognitive facets of our linguistic abilities (auditory, vocal, attention, and memory systems).

\section{GENOME: OXT MODULATES GENES INVOLVED IN SPOKEN-LANGUAGE ACQUISITION}

Apart from the aforementioned actions of OXT, what is of most relevance for the present article is its key role in several developmental processes that subserve the acquisition of our higher cognitive skills. Oxytocin-mediated, experiencedependent cross-modal plasticity in the sensory cortices during early development (Zheng et al., 2014) and the left-lateralized expression of OXT in the auditory cortex of the mouse brain (Marlin et al., 2015) suggest that OXT pathways are highly pertinent to understanding the sensory ontogeny of our linguistic communication. For humans, epigenetic misregulation of the OXTR via aberrant gene silencing with DNA methylation has implicated OXT in the development of Autism Spectrum Disorder, where deficits in language performance are included in its core phenotype (Gregory et al., 2009). A potential mechanism is that epigenetic DNA methylation of the oxytocin receptor gene (OXTR) is associated with neural activity and functional coupling of neurons (Puglia et al., 2015). Thus, the aberrant OXTR expression by methylation could be impacting neural activity and neuronal coupling in language performance.

An even more possible direct genetic link between OXT and our linguistic capacities is evidenced in the robust findings with genes known to be necessary for normal language development, namely in the FOXP2-CNTNAP2 pathway. To begin with, interaction between OXT and CNTNAP2 in critical developmental windows has been shown in a mouse model of autism (Peñagarikano et al., 2015). FOXP2 regulates CNTNAP2 expression, and CNTNAP2 has been linked to complex neurological disorders, including language impairment, autism, dyslexia, schizophrenia, and depression, with Single Nucleotide Polymorphisms (SNPs) having been associated with specific language endophenotypes (see Rodenas-Cuadrado et al., 2014 for review).

Another link between OXT and FOXP2 is provided through LNPEP, the peptidase that metabolizes oxytocin, located on chromosome 5q15 (for more details on LNPEP see Ebstein et al., 2012). Vernes et al. (2007) identified genomic sites directly bound by FOXP2 protein in native chromatin of human neuron-like cells, and LNPEP was among the genes with the most robust and consistent binding. LNEP functionally regulates synaptic transmission and formation.

A third potential interaction between OXT and FOXP2 may occur by two other genes related to language: (i) RUNX2 and (ii) POU3F2 (Benítez-Burraco and Boeckx, 2014, 2015). For RUNX2, - a critical transcription factor for osteoblast formation-, Tamma et al. (2009) found that it was differentially regulated in OXT knockout mice. RUNX2 is connected to many genes that are essential not only for brain and language development, but also for bone formation (Boeckx and Benítez-Burraco, 2015). A direct interaction between RUNX2 and FOXP2 has been experimentally demonstrated in the context of endochondral ossification (Zhao et al., 2015), a finding further reinforced by Gascoyne et al. (2015), who added FOXP2 to the list of established osteoblast and chondrocyte transcription factors (such as RUNX2). Significantly, the action of OXT on osteoblast maturation (Di Benedetto et al., 2014) and its implication in an osteogenic network that supports the development of our language-ready brain (and skull) may provide genetic evidence for the hypothesis that OXT may directly foster encephalization and our craniofacial phenotype (Carter, 2014). Last but not least, both OXT and RUNX2 have been found to be strongly connected to the Vitamin D endocrine system (Prüfer and Jirikowski, 1997; Han et al., 2013; Patrick and Ames, 2014), which has been proposed to explain the genetics and epidemiology of Autism (Cannell, 2008).

Concerning POU3F2, a transcription factor, neuronal and endocrine components (including OXT) of the hypothalamicpituitary axis have been shown to be critically dependent on POU3F2 action (Nakai et al., 1995; Schonemann et al., 1995; Burbach et al., 2001). POU3F2 also regulates FOXP2 gene expression in a human-specific manner (Maricic et al., 2013). Crucially, the fact that in all three genes, OXTR, POU3F2, and FOXP2, there have been identified signs of positive selection in human or recent hominin evolution (Enard et al., 2002; Maricic et al., 2013; Schaschl et al., 2015), reinforces the idea that these evolutionary changes might be partially responsible for the emergence of aspects of our species-specific cognitive and linguistic abilities. 


\section{CONNECTOME}

Recent studies have implicated OXT in brain development and plasticity. Specifically, the oxytocinergic brain system has been described to undergo major morphological alterations that modify the conformation of its neurons and glia and its synaptic inputs in a stimulus-dependent manner (Theodosis, 2002). The bulk of the evidence coming from studies in mice, rats and praire voles elucidates the significant role OXT plays in shaping different pathways of the brain (see Carter, 2003 for review). Importantly, the expression of the OXTR displays a particular maturational progression in the brain of the developing rat that could be classified in two types: transient expression during early postnatal development and constant abundant expression mediating neuronal transmission in the mature brain (Yoshimura et al., 1996). Similarly in mice, neocortical OXTR binding exhibits a transient peak in early postnatal periods, when extensive synaptic proliferation and pruning takes place (Hammock and Levitt, 2013).

These findings along with the ones that address the effect of the maturation of the OXT system on sensory-and not only socio-sexual- aspects could exemplify why early postnatal life is indeed a sensitive period for OXT in modeling circuits that are eventually responsible for sensory performance. Additional insight can be gained from comparative data on mice: Zheng et al. (2014) found that OXT promotes excitatory synaptic transmission in the sensory cortices at a much earlier stage than the hitherto understood functions of OXT in social and emotional contexts and, notably, Marlin et al. (2015) found that both OXT receptors and projections from hypothalamic OXTproducing neurons are present in the auditory cortex of mice, with the former being more numerous on the left side than on the right, something that could be telling for lateralization in human language development (Theofanopoulou, 2015 and references therein).

In humans, it has not yet been experimentally established how early adjustments of the OXT system influence the neuronal and synaptic substrates that underlie the sensory and cognitive modules of our language-ready brain. The only (rough) conclusions we can deduce from the literature are based on comparisons between infants that have or have not been breastfed and concomitant brain changes. On the grounds that OXT is stable in milk and that OXT in maternal blood can be transferred to milk and then to neonates (Takeda et al., 1986), we would expect that lactation goes hand-in-hand with proliferating brain connectivity. At least, some evidence suggests so: Deoni et al. (2013) showed an association between early exclusive breastfeeding with increased development in late maturing white matter regions (interestingly also near BA44, traditionally linked to language). Tellingly, breastfed children also showed improved receptive language scores compared to formula-fed children. Moreover, Khedr et al. (2004) found that visual evoked potential (FVEP), brainstem auditory evoked potential (BAEP), and somatosensory evoked potential (SSEP) are more mature in breastfed infants relative to formula-fed infants at 1-year of age, something suggestive of the importance of breastfeeding in early development. I propose that an important molecule and factor could be the high concentration in OXT in breast milk and also its release during skin-to-skin contact over breastfeeding (UvnäsMoberg et al., 2015). Furthermore, the aforementioned results (see also Kafouri et al., 2013 and Isaacs et al., 2010) mesh well with recent studies showing that autism is to a great extent correlated with inefficient breastfeeding, by cause of lack of interest in milk-suckling (Williams et al., 2000; Gallup and Hobbs, 2011; Al-Farsi et al., 2012; Steinman and Mankuta, 2013). A deeper understanding of the complex OXT feedback loop between mother and infant in breastfeeding could be reached if we additionally take into account that the perturbation of the system might be actually stemming from the mother. Indeed, birth complications (Brimacombe et al., 2007) due to low OXT levels and stressful-depressive mother care have long been associated with autism (see Uvnäs-Moberg et al., 2015 for an excellent review on the short- and long-term effects of breastfeeding and skin-to-skin contact between mother and infant, explained via OXT release). According to this thread of interpretation, traditional psychological theories on the role of the "refrigeratormother" in the etiology of autism could now be construed on a neuroendocrine basis.

Another important issue at the level of the connectome is the loci where OXT is expressed in the brain. In humans, OXT is dispersed from the magnocellular neurons in the paraventricular and supraoptic nuclei of the hypothalamus to practically throughout the brain: including the amygdala, the hippocampus, the striatum, the brainstem, the cerebellum, the insula, the suprachiasmatic nucleus, the septum, the bed nucleus of stria terminalis, the globus pallidus, the substantia nigra pars compacta, the ventral tegmental are, the spinal cord, and to neocortical areas traditionally associated with "language," such as the prefrontal cortex, the anterior cingulate cortex and the precuneus (Lee et al., 2009, 2010; Ma et al., 2016). Even though it is important to find out "where" OXT is expressed in the brain, a mere locationist approach cannot enlighten our understanding of "how" OXT gives rise to cognitive subprocesses mechanistically (Theofanopoulou and Boeckx, 2015). At the following level of analysis (i.e., the dynome) the direct effects of OXT administration on brain rhythms and how this translates into specific cognitive processes (i.e., the cognome) will be illustrated.

\section{DYNOME-COGNOME}

Only very recently attempts have been made to link the action of OXT with a rhythmic correlate in the human brain that would make some sense in terms of its cognitive significance. In early experimental attempts of pure behavioral paradigms (e.g., "trust" experiments, for example: Baumgartner et al., 2008), OXT was not implicated at a granularity level that could be matched with the (de)activation of a specific oscillatory band. It was not until 2009, when Kéri and Benedek examined the effect of OXT on the perception of biological vs. non-biological motion stimuli, that a venue for associating OXT modulation to neural activity was opened (Kéri and Benedek, 2009). Specifically, Kéri and Benedek found that OXT enhances the ability to detect biological motion in noise, whereas no such effect turned up when detecting a 
rotating shape. This led Perry et al. (2010) to tentatively link these results with the alpha/mu and beta brain rhythms, which have been shown to be suppressed while observing actions executed by someone else (Muthukumaraswamy and Johnson, 2004; Lange et al., 2015). Characteristically, alpha/mu and beta rhythms have been found to be desynchronized reinforcing the efficiency of the mirror neuron system, which in humans is activated not only when observing biological actions, but also at all levels of communicative interactions (see Pineda, 2005 for a review). This is more than pertinent to the scope of this article, since for linguistic communication interplay to happen, it is necessary not only to perceive biological movements (lip-movements, tongue-movements, formant transitions, hand gestures, and eye movements), but to couple them with the auditory input and whence make out the multidimensional meaning of the compound "linguistic" input. As I have put forward elsewhere (Theofanopoulou, 2015), this interplay should be mediated by an attentional mechanism that keeps track of all these distinct rhythmic stimuli. It should not take us by surprise then that an overall decrease of the aforesaid rhythms has also been linked to increased demands of attention and memory (Klimesch, 2012). Importantly, after OXT administration, alpha/mu and beta rhythms had a general suppressive effect that was widespread across the scalp (viz not only on brain areas of the somato-motor cortex), something that was interpreted as an effect on a broader network, in which mirror/motor and attentional mechanisms can be with difficultly disentangled (Perry et al., 2010). A similar experiment was conducted by Singh et al. (2015), also in Schizophrenia patients, and replicated the diffused effect of OXT in the brain. Lastly, Hepker (2016) tested how OXT affects mirror neuron activity in a hand-gesture experiment and encountered greater mu rhythm suppression, in accordance with other experiments, but this time for a biological movement directly involved in language processing.

To the best of my knowledge, there are no studies yet showing that OXT has a direct effect on the rhythmic patterns in a purely linguistic task. But as put forth in Theofanopoulou (2016) there are several reasons to expect so. Firstly, alpha/mu and beta band suppression have been shown to coordinate the rhythms partaking not only in motor but also in auditory (speech) (Obleser and Weisz, 2012) processing and OXT seems to support this multimodality, considering that it has been found to increase not only in response to biological motions, but also to vocalizations alone (Seltzer et al., 2010) and to attenuate the human acoustic startle response (Ellenbogen et al., 2014). Secondly, in autism alpha-band deployment was shown to be severely impaired, giving rise to increased distraction (Oberman et al., 2005, 2008; Murphy et al., 2014; see also Moran and Hong, 2011, for similar findings in schizophrenia). Here magnetoencephalography (MEG) studies showing atypical auditory responses in patients with autism are also of relevance: for example, in autistic patients stronger responses to nonspeech than speech sounds (Yau et al., 2015), delayed (Roberts et al., 2010), and atypically lateralized (Orekhova et al., 2012) neuromagnetic auditory field responses compared to controls were observed. These experiments in conjunction with the irregularities observed in the oxytocinergic system in autism make it plausible that OXT might in part modulate the brain rhythms in language-processing.

\section{PHENOME}

In behavioral experiments OXT has been engaged in a surfeit of different complex tasks that can be difficult to decompose for the aims of this article. Accordingly, only experiments that are informative for different facets of linguistic processing will be mentioned.

OXT has been loosely associated with "communicative" functions (Yamasue, 2013) that only recently have been broken down into processes that correspond to more specific linguistic processes. For instance, Seltzer et al. (2010) found that children under stress show increased OXT levels after hearing maternal vocalizations and Watanabe et al. (2014) showed that intranasal OXT administration to autism-patients affects their decisions about social information with conflicting verbal and non-verbal contents. Lastly, Ellenbogen et al. (2014) found that intranasal oxytocin attenuates the human acoustic startle response independent of emotional modulation.

However, most data come from studies involving OXT in eyegaze enhancement suggesting its plausible role in interpersonal communication (Guastella et al., 2008) and in inferring the mental state of others (Domes et al., 2007). Gamer (2010) explains that OXT increased the proportion of fixation changes toward the eyes across all expressions, and did not directly affect the efficiency of processing emotional faces per se. In light of studies clarifying the importance of eye gaze in the modulation of speech and co-speech gesture (Holler et al., 2014, 2015), we can better appraise why in most cases the communicative deficits in autism derive from an abnormal fixation to the mouth region of the interlocutor, instead of the eye region (Pelphrey et al., 2005; Neumann et al., 2006). Tellingly, for therapeutic concerns, Andari et al. (2010) found that OXT selectively increased autism patients' gazing time on the eye region, improving their social performance.

In a similar vein, Ebitz and Platt (2014) further argue that these emitted eye-signals, regulated by OXT, provoke OXTrelease back in the receiver, increasing eye contact and proximity seeking, establishing in this way a back-and-forward loop that strongly underlies communicative functions. This cascade of reciprocal OXT-secretion might, in other words, give a neurohormonal basis to the "turn-taking" roots of our linguistic capacity, recently highlighted from an evolutionary perspective (Levinson, 2016).

\section{CONCLUSION}

In this article I attempted to draw attention to the potential implications of the neurohormone OXT in the context of language. Even though its role in purely linguistic matters has so far been overlooked, there is already a plethora of evidence strongly suggesting that a better understanding of its function could be rewarding. Results from experiments at different levels of analysis (from genetic to oscillatory and behavioral) suggest 
that OXT could fit well in the recently addressed hypotheses that underline the "reward-learning" foundations of our linguistic capacities (see Berra, 2015 for a good review). However, till now only dopamine has been tested in linguistic tasks in humans (Ripollés et al., 2014) and widely in vocal-learning in zebra finches (reviewed in Simonyan et al., 2012). More genetic experiments on the effect of OXT on mice vocalizations and birdsongs in different paradigms (courtship, affiliative, fear, dam-puppies) and EEG studies on its impact on alpha/mu/beta rhythm suppression in a speech perception task would help to appreciate more the role of OXT in our high cognition and its possible therapeutic implications.

\section{AUTHOR CONTRIBUTIONS}

The author confirms being the sole contributor of this work and approved it for publication.

\section{REFERENCES}

Al-Farsi, Y. M., Al-Sharbati, M. M., Waly, M. I., Al-Farsi, O. A., Al-Shafaee, M. A., Al-Khaduri, M. M., et al. (2012). Effect of suboptimal breast-feeding on occurrence of autism: a case-control study. Nutrition 28, e27-e32. doi: 10.1016/j.nut.2012.01.007

Andari, E., Duhamel, J.-R., Zalla, T., Herbrecht, E., Leboyer, M., and Sirigu, A. (2010). Promoting social behavior with oxytocin in high-functioning autism spectrum disorders. Proc. Natl. Acad. Sci. U.S.A. 107, 4389-4394. doi: 10.1073/pnas.0910249107

Baumgartner, T., Heinrichs, M., Vonlanthen, A., Fischbacher, U., and Fehr, E. (2008). Oxytocin shapes the neural circuitry of trust and trust adaptation in humans. Neuron 58, 639-650. doi: 10.1016/j.neuron.2008.04.009

Benítez-Burraco, A., and Boeckx, C. (2014). FOXP2, retinoic acid, and language: a promising direction. Front. Cell. Neurosci. 8:387. doi: 10.3389/fncel.2014.00387

Benítez-Burraco, A., and Boeckx, C. (2015). Possible functional links among brainand skull-related genes selected in modern humans. Front. Psychol. 6:794. doi: 10.3389/fpsyg.2015.00794

Berra, I. (2015). Emotions in vocal learning. The continuity behind the convergence. Reti Saperi Linguaggi. 1, 167-184. doi: 10.12832/81296

Boeckx, C., and Benítez-Burraco, A. (2015). Osteogenesis and neurogenesis: a robust link also for language evolution. Front. Cell. Neurosci. 9:291. doi: 10.3389/fncel.2015.00291

Brimacombe, M., Ming, X., and Lamendola, M. (2007). Prenatal and birth complications in autism. Matern. Child Health J. 11, 73-79. doi: 10.1007/s10995-006-0142-7

Burbach, J. P. H., Luckman, S. M., Murphy, D., and Gainer, H. (2001). Gene regulation in the magnocellular hypothalamo-neurohypophysial system. Physiol. Rev. 81, 1197-1267.

Cannell, J. J. (2008). Autism and vitamin D. Med. Hypotheses 70, 750-759. doi: 10.1016/j.mehy.2007.08.016

Carter, C. S. (2003). Developmental consequences of oxytocin. Physiol. Behav. 79, $383-397$.

Carter, C. S. (2014). Oxytocin pathways and the evolution of human behavior. Annu. Rev. Psychol. 65, 17-39. doi: 10.1146/annurev-psych-010213-115110

De Berardis, D., Marini, S., Iasevoli, F., Tomasetti, C., de Bartolomeis, A., Mazza, M., et al. (2013). The role of intranasal oxytocin in the treatment of patients with schizophrenia: a systematic review. CNS Neurol. Disord. Drug Targets 12, $252-264$.

Deoni, S. C. L., Dean, D. C., Piryatinsky, I., O’Muircheartaigh, J., Waskiewicz, N., Lehman, K., et al. (2013). Breastfeeding and early white matter development: a cross-sectional study. Neuroimage 82, 77-86. doi: 10.1016/j.neuroimage.2013.05.090

\section{FUNDING}

Preparation of this work was supported by funds from the Spanish Ministry of Economy and Competitiveness (grant FFI2013-43823-P), as well as funds from the Generalitat de Catalunya (FI-grant-20162019).

\section{ACKNOWLEDGMENTS}

I am indebted to my advisor, Cedric Boeckx, for his constant support and help. I would also like to thank my co-advisor Erich Jarvis for his valuable comments and instructive discussions, Olga Peñagarikano for helpful information on the genetics of oxytocin and Sonja Vernes for very fruitful conversations on the genetics of language. Lastly, I am grateful to David Poeppel for his comments on how the rhythmic effect of oxytocin should be tested.

Di Benedetto, A., Sun, L., Zambonin, C. G., Tamma, R., Nico, B., Calvano, C. D., et al. (2014). Osteoblast regulation via ligand-activated nuclear trafficking of the oxytocin receptor. Proc. Natl. Acad. Sci. U.S.A. 111, 16502-16507. doi: 10.1073/pnas.1419349111

Domes, G., Heinrichs, M., Michel, A., Berger, C., and Herpertz, S. C. (2007). Oxytocin improves "mind-reading" in humans. Biol. Psychiatry 61, 731-733. doi: 10.1016/j.biopsych.2006.07.015

Ebitz, R. B., and Platt, M. M. (2014). An evolutionary perspective on the behavioral consequences of exogenous oxytocin application. Front. Behav. Neurosci. 7:225. doi: 10.3389/fnbeh.2013.00225

Ebstein, R. P., Knafo, A., Mankuta, D., Chew, S. H., and Lai, P. S. (2012). The contributions of oxytocin and vasopressin pathway genes to human behavior. Horm. Behav. 61, 359-379. doi: 10.1016/j.yhbeh.2011.12.014

Ellenbogen, M. A., Linnen, A.-M., Cardoso, C., and Joober, R. (2014). Intranasal oxytocin attenuates the human acoustic startle response independent of emotional modulation. Psychophysiology 51, 1169-1177. doi: 10.1111 psyp.12263

Enard, W., Przeworski, M., Fisher, S. E., Lai, C. S. L., Wiebe, V., Kitano, T., et al. (2002). Molecular evolution of FOXP2, a gene involved in speech and language. Nature 418, 869-872. doi: 10.1038/nature01025

Fisher, S. E. (2015). "Translating the genome in human neuroscience," in The Future of the Brain: Essays by the World's Leading Neuroscientists, eds G. Marcus and J. Freeman (Princeton, NJ: Princeton University Press), 149-159.

Gallup, G. G., and Hobbs, D. R. (2011). Evolutionary medicine: bottle feeding, birth spacing, and autism. Med. Hypotheses 77, 345-346. doi: 10.1016/j.mehy.2011.05.010

Gamer, M. (2010). Does the amygdala mediate oxytocin effects on socially reinforced learning? J. Neurosci. 30, 9347-9348. doi: 10.1523/JNEUROSCI. 2847-10.2010

Gascoyne, D. M., Spearman, H., Lyne, L., Puliyadi, R., Perez-Alcantara, M., Coulton, L., et al. (2015). The forkhead transcription factor FOXP2 is required for regulation of p21WAF1/CIP1 in 143B osteosarcoma cell growth arrest. PLoS ONE 10:e0128513. doi: 10.1371/journal.pone.0128513

Gregory, S. G., Connelly, J. J., Towers, A. J., Johnson, J., Biscocho, D., Markunas, C. A., et al. (2009). Genomic and epigenetic evidence for oxytocin receptor deficiency in autism. BMC Med. 7:62. doi: 10.1186/1741-7015-7-62

Grinevich, V., Desarménien, M. G., Chini, B., Tauber, M., and Muscatelli, F. (2015). Ontogenesis of oxytocin pathways in the mammalian brain: late maturation and psychosocial disorders. Front. Neuroanat. 8:164. doi: 10.3389/fnana.2014.00164

Guastella, A. J., Mitchell, P. B., and Dadds, M. R. (2008). Oxytocin increases gaze to the eye region of human faces. Biol. Psychiatry 63, 3-5. doi: 10.1016/j.biopsych.2007.06.026 
Haas, B. W., and Smith, A. K. (2015). Oxytocin, vasopressin, and Williams syndrome: epigenetic effects on abnormal social behavior. Front. Genet. 6:28. doi: 10.3389/fgene. 2015.00028

Hammock, E. A. D., and Levitt, P. (2013). Oxytocin receptor ligand binding in embryonic tissue and postnatal brain development of the C57BL/6J mouse. Front. Behav. Neurosci. 7:195. doi: 10.3389/fnbeh.2013.00195

Han, M.-S., Che, X., Cho, G., Park, H.-R., Lim, K.-E., Park, N.-R., et al. (2013). Functional cooperation between vitamin D receptor and Runx2 in vitamin D-induced vascular calcification. PLoS ONE 8:e83584. doi: 10.1371/journal.pone.0083584

Hepker, M. (2016). "Effect of oxytocin administration on mirror neuron activation," in Summer Research. Paper 176. Available online at: http://soundideas.pugetsound.edu/summer_research/176

Holler, J., Kokal, I., Toni, I., Hagoort, P., Kelly, S. D., and Özyürek, A. (2015). Eye'm talking to you: speakers' gaze direction modulates co-speech gesture processing in the right MTG. Soc. Cogn. Affect. Neurosci. 10, 255-261. doi: $10.1093 / \mathrm{scan} / \mathrm{nsu} 047$

Holler, J., Schubotz, L., Kelly, S., Hagoort, P., Schuetze, M., and Özyürek, A. (2014). Social eye gaze modulates processing of speech and co-speech gesture. Cognition 133, 692-697. doi: 10.1016/j.cognition.2014.08.008

Isaacs, E. B., Fischl, B. R., Quinn, B. T., Chong, W. K., Gadian, D. G., and Lucas, A. (2010). Impact of breast milk on IQ, brain size and white matter development. Pediatr. Res. 67, 357-362. doi: 10.1203/PDR.0b013e3181d026da

Kafouri, S., Kramer, M., Leonard, G., Perron, M., Pike, B., Richer, L., et al. (2013). Breastfeeding and brain structure in adolescence. Int. J. Epidemiol. 42, 150-159. doi: 10.1093/ije/dys172

Kéri, S., and Benedek, G. (2009). Oxytocin enhances the perception of biological motion in humans. Cogni. Affect. Behav. Neurosci. 9, 237-241. doi: 10.3758/CABN.9.3.237

Khedr, E., Farghaly, W., Amry, S. E.-D., and Osman, A. (2004). Neural maturation of breastfed and formula-fed infants. Acta Paediatr. 93, 734-738. doi: 10.1111/j.1651-2227.2004.tb03011.x

Klimesch, W. (2012). $\alpha$-band oscillations, attention, and controlled access to stored information. Trends Cogn. Sci. 16, 606-617. doi: 10.1016/j.tics.2012.10.007

Lange, J., Pavlidou, A., and Schnitzler, A. (2015). Lateralized modulation of betaband power in sensorimotor areas during action observation. Front. Integr. Neurosci. 9:43. doi: 10.3389/fnint.2015.00043

Leckman, J. F., Goodman, W. K., North, W. G., Chappell, P. B., Price, L. H., Pauls, D. L., et al. (1994). The role of central oxytocin in obsessive compulsive disorder and related normal behavior. Psychoneuroendocrinology 19, 723-749.

Lee, H.-J., Macbeth, A. H., Pagani, J. H., and Young, W. S. (2009). Oxytocin: the great facilitator of life. Prog. Neurobiol. 88, 127-151. doi: 10.1016/j.pneurobio.2009.04.001

Lee, H.-J., Pagani, J., and Young, W. S. (2010). Using transgenic mouse models to study oxytocin's role in the facilitation of species propagation. Brain Res. 1364, 216-224. doi: 10.1016/j.brainres.2010.08.042

Levinson, S. C. (2016). Turn-taking in human communication - origins and implications for language processing. Trends Cogn. Sci. 20, 6-14. doi: 10.1016/j.tics.2015.10.010

Lopatina, O., Inzhutova, A., Salmina, A. B., and Higashida, H. (2012). The roles of oxytocin and CD38 in social or parental behaviors. Front. Neurosci. 6:182. doi: $10.3389 /$ fnins. 2012.00182

Ma, Y., Shamay-Tsoory, S., Han, S., and Zink, C. F. (2016). Oxytocin and social adaptation: insights from neuroimaging studies of healthy and clinical populations. Trends Cogn. Sci. 20, 133-145. doi: 10.1016/j.tics.2015.10.009

Maricic, T., Günther, V., Georgiev, O., Gehre, S., Curlin, M., Schreiweis, C., et al. (2013). A recent evolutionary change affects a regulatory element in the human FOXP2 gene. Mol. Biol. Evol. 30, 844-852. doi: 10.1093/molbev/mss271

Marlin, B. J., Mitre, M., D'amour, J. A., Chao, M. V., and Froemke, R. C. (2015). Oxytocin enables maternal behaviour by balancing cortical inhibition. Nature 520, 499-504. doi: 10.1038/nature14402

Meyer-Lindenberg, A., Domes, G., Kirsch, P., and Heinrichs, M. (2011). Oxytocin and vasopressin in the human brain: social neuropeptides for translational medicine. Nat. Rev. Neurosci. 12, 524-538. doi: 10.1038/nrn3044

Moran, L. V., and Hong, L. E. (2011). High vs low frequency neural oscillations in schizophrenia. Schizophr. Bull. 37, 659-663. doi: 10.1093/schbul/sbr056

Murphy, J. W., Foxe, J. J., Peters, J. B., and Molholm, S. (2014). Susceptibility to distraction in autism spectrum disorder: probing the integrity of oscillatory alpha-band suppression mechanisms. Autism Res. 7, 442-458. doi: 10.1002/aur.1374

Muthukumaraswamy, S. D., and Johnson, B. W. (2004). Changes in rolandic mu rhythm during observation of a precision grip. Psychophysiology 41, 152-156. doi: 10.1046/j.1469-8986.2003.00129.x

Nakai, S., Kawano, H., Yudate, T., Nishi, M., Kuno, J., Nagata, A., et al. (1995). The POU domain transcription factor Brn-2 is required for the determination of specific neuronal lineages in the hypothalamus of the mouse. Genes Dev. 9, 3109-3121.

Neumann, D., Spezio, M. L., Piven, J., and Adolphs, R. (2006). Looking you in the mouth: abnormal gaze in autism resulting from impaired top-down modulation of visual attention. Soc. Cogn. Affect. Neurosci. 1, 194-202. doi: $10.1093 / \mathrm{scan} / \mathrm{nsl} 030$

Oberman, L. M., Hubbard, E. M., McCleery, J. P., Altschuler, E. L., Ramachandran, V. S., and Pineda, J. A. (2005). EEG evidence for mirror neuron dysfunction in autism spectrum disorders. Brain Res. Cogn. Brain Res. 24, 190-198. doi: 10.1016/j.cogbrainres.2005.01.014

Oberman, L. M., Ramachandran, V. S., and Pineda, J. A. (2008). Modulation of mu suppression in children with autism spectrum disorders in response to familiar or unfamiliar stimuli: the mirror neuron hypothesis. Neuropsychologia 46, 1558-1565. doi: 10.1016/j.neuropsychologia.2008.01.010

Obleser, J., and Weisz, N. (2012). Suppressed alpha oscillations predict intelligibility of speech and its acoustic details.Cereb. Cortex 22, 2466-2477. doi: $10.1093 /$ cercor/bhr325

Orekhova, E. V., Tsetlin, M. M., Butorina, A. V., Novikova, S. I., Gratchev, V. V., Sokolov, P. A., et al. (2012). Auditory cortex responses to clicks and sensory modulation difficulties in children with Autism Spectrum Disorders (ASD). PLoS ONE 7:e39906. doi: 10.1371/journal.pone.0039906

Patrick, R. P., and Ames, B. N. (2014). Vitamin D hormone regulates serotonin synthesis. Part 1: relevance for autism. FASEB J. 28, 2398-2413. doi: 10.1096/fj.13-246546

Pelphrey, K. A., Morris, J. P., and McCarthy, G. (2005). Neural basis of eye gaze processing deficits in autism. Brain 128(Pt 5), 1038-1048. doi: 10.1093/brain/awh404

Peñagarikano, O., Lázaro, M. T., Lu, X.-H., Gordon, A., Dong, H., Lam, H. A., et al. (2015). Exogenous and evoked oxytocin restores social behavior in the Cntnap2 mouse model of autism. Sci. Transl. Med. 7, 271ra8. doi: 10.1126/scitranslmed.3010257

Perry, A., Bentin, S., Shalev, I., Israel, S., Uzefovsky, F., Bar-On, D., et al. (2010). Intranasal oxytocin modulates EEG mu/alpha and beta rhythms during perception of biological motion. Psychoneuroendocrinology 35, 1446-1453. doi: 10.1016/j.psyneuen.2010.04.011

Pineda, J. A. (2005). The functional significance of mu rhythms: translating "seeing" and "hearing" into "doing." Brain Research. Brain Res. Rev. 50, 57-68. doi: 10.1016/j.brainresrev.2005.04.005

Prüfer, K., and Jirikowski, G. F. (1997). 1.25-Dihydroxyvitamin D3 receptor is partly colocalized with oxytocin immunoreactivity in neurons of the male rat hypothalamus. Cell. Mol. Biol. 43, 543-548.

Puglia, M. H., Lillard, T. S., Morris, J. P., and Connelly, J. J. (2015). Epigenetic modification of the oxytocin receptor gene influences the perception of anger and fear in the human brain. Proc. Natl. Acad. Sci. U.S.A. 112, 3308-3313. doi: 10.1073/pnas.1422096112

Ripollés, P., Marco-Pallarés, J., Hielscher, U., Mestres-Missé, A., Tempelmann, C., Heinze, H.-J., et al. (2014). The role of reward in word learning and its implications for language acquisition. Curr. Biol. 24, 2606-2611. doi: 10.1016/j.cub.2014.09.044

Roberts, T. P. L., Khan, S. Y., Rey, M., Monroe, J. F., Cannon, K., Blaskey, L., et al. (2010). MEG detection of delayed auditory evoked responses in autism spectrum disorders: towards an imaging biomarker for autism. Autism Res. 3, 8-18. doi: 10.1002/aur.111

Rodenas-Cuadrado, P., Ho, J., and Vernes, S. C. (2014). Shining a light on CNTNAP2: complex functions to complex disorders. Eur. J. Hum. Genet. 22, 171-178. doi: 10.1038/ejhg.2013.100

Schaschl, H., Huber, S., Schaefer, K., Windhager, S., Wallner, B., and Fieder, M. (2015). Signatures of positive selection in the cis-regulatory sequences of the human oxytocin receptor (OXTR) and arginine vasopressin receptor la (AVPR1A) genes. BMC Evol. Biol. 15:85. doi: 10.1186/s12862-0150372-7 
Schonemann, M. D., Ryan, A. K., McEvilly, R. J., O'Connell, S. M., Arias, C. A., Kalla, K. A., et al. (1995). Development and survival of the endocrine hypothalamus and posterior pituitary gland requires the neuronal POU domain factor Brn-2. Genes Dev. 9, 3122-3135.

Seltzer, L. J., Ziegler, T. E., and Pollak, S. D. (2010). Social vocalizations can release oxytocin in humans. Proc. Biol. Sci. 277, 2661-2666. doi: 10.1098/rspb.2010.0567

Simonyan, K., Horwitz, B., and Jarvis, E. D. (2012). Dopamine regulation of human speech and bird song: a critical review. Brain Lang. 122, 142-150. doi: 10.1016/j.bandl.2011.12.009

Singh, F., Nunag, J., Muldoon, G., Cadenhead, K. S., Pineda, J. A., and Feifel, D. (2015). Effects of intranasal oxytocin on neural processing within a socially relevant neural circuit. Eur. Neuropsychopharmacol. 26, 626-630. doi: 10.1016/j.euroneuro.2015.12.026

Steinman, G., and Mankuta, D. (2013). Breastfeeding as a possible deterrent to autism-a clinical perspective. Med. Hypotheses 81, 999-1001. doi: 10.1016/j.mehy.2013.09.013

Takeda, S., Kuwabara, Y., and Mizuno, M. (1986). Concentrations and origin of oxytocin in breast milk. Endocrinol. Jpn. 33, 821-826.

Tamma, R., Colaianni, G., Zhu, L., DiBenedetto, A., Greco, G., Montemurro, G., et al. (2009). Oxytocin is an anabolic bone hormone. Proc. Natl. Acad. Sci. U.S.A. 106, 7149-7154. doi: 10.1073/pnas.0901890106

Theodosis, D. T. (2002). Oxytocin-secreting neurons: a physiological model of morphological neuronal and glial plasticity in the adult hypothalamus. Front. Neuroendocrinol. 23, 101-135. doi: 10.1006/frne.2001.0226

Theofanopoulou, C. (2015). Brain asymmetry in the white matter making and globularity. Front. Psychol. 6:1355. doi: 10.3389/fpsyg.2015.01355

Theofanopoulou, C. (2016). "Why oxytocin might affect rhythmicity," in EVOLANG 11 Workshop: Rhythm: Development, Evolution and Cognition (New Orleans, LA: Tulane University).

Theofanopoulou, C., and Boeckx, C. (2015). Cognitive phylogenies, the Darwinian logic of descent, and the inadequacy of cladistic thinking. Front. Cell Dev. Biol. 3:64. doi: $10.3389 /$ fcell.2015.00064

Uvnäs-Moberg, K., Handlin, L., and Petersson, M. (2015). Self-soothing behaviors with particular reference to oxytocin release induced by nonnoxious sensory stimulation. Front. Psychol. 5:1529. doi: 10.3389/fpsyg.2014. 01529
Vernes, S. C., Spiteri, E., Nicod, J., Groszer, M., Taylor, J. M., Davies, K. E., et al. (2007). High-throughput analysis of promoter occupancy reveals direct neural targets of FOXP2, a gene mutated in speech and language disorders. Am. J. Hum. Genet. 81, 1232-1250. doi: 10.1086/522238

Watanabe, T., Abe, O., Kuwabara, H., Yahata, N., Takano, Y., Iwashiro, N., et al. (2014). Mitigation of sociocommunicational deficits of autism through oxytocin-induced recovery of medial prefrontal activity: a randomized trial. JAMA Psychiatry 71, 166-175. doi: 10.1001/jamapsychiatry. 2013.3181

Williams, P. G., Dalrymple, N., and Neal, J. (2000). Eating habits of children with autism. Pediatr. Nurs. 26, 259-264.

Yamasue, H. (2013). Function and structure in social brain regions can link oxytocin-receptor genes with autistic social behavior. Brain Dev. 35, 111-118. doi: 10.1016/j.braindev.2012.08.010

Yau, S. H., McArthur, G., Badcock, N. A., and Brock, J. (2015). Case study: auditory brain responses in a minimally verbal child with autism and cerebral palsy. Front. Neurosci. 9:208. doi: 10.3389/fnins.2015.00208

Yoshimura, R., Kimura, T., Watanabe, D., and Kiyama, H. (1996). Differential expression of oxytocin receptor mRNA in the developing rat brain. Neurosci. Res. 24, 291-304. doi: 10.1016/0168-010201003-3

Zhao, H., Zhou, W., Yao, Z., Wan, Y., Cao, J., Zhang, L., et al. (2015). Foxp1/2/4 regulate endochondral ossification as a suppresser complex. Dev. Biol. 398, 242-254. doi: 10.1016/j.ydbio.2014.12.007

Zheng, J.-J., Li, S.-J., Zhang, X.-D., Miao, W.-Y., Zhang, D., Yao, H., et al. (2014). Oxytocin mediates early experience-dependent cross-modal plasticity in the sensory cortices. Nat. Neurosci. 17, 391-399. doi: 10.1038/nn.3634

Conflict of Interest Statement: The author declares that the research was conducted in the absence of any commercial or financial relationships that could be construed as a potential conflict of interest.

Copyright (c) 2016 Theofanopoulou. This is an open-access article distributed under the terms of the Creative Commons Attribution License (CC BY). The use, distribution or reproduction in other forums is permitted, provided the original author(s) or licensor are credited and that the original publication in this journal is cited, in accordance with accepted academic practice. No use, distribution or reproduction is permitted which does not comply with these terms. 